\title{
Surface Conversion Effects in Plasma-Damaged p-GaN
}

\author{
X.A. Cao ${ }^{1}$, S.J. Pearton', G.T. Dang ${ }^{2}$, A.P. Zhang ${ }^{2}$, F. Ren ${ }^{2}$, R.J. Shul ${ }^{3}$, L. Zhang ${ }^{3}$, R. \\ Hickman ${ }^{4}$ and J.M. Van Hove ${ }^{4}$ \\ ${ }^{1}$ Dept. Materials Science and Engineering \\ University of Florida, Gainesville, FL 32611 \\ ${ }^{2}$ Dept. Chemical Engineering \\ University of Florida, Gainesville, FL 32611 \\ ${ }^{3}$ Sandia National Laboratories, Albuquerque, NM 87185 \\ ${ }^{4}$ SVT Associates, Eden Prairie, MN 55344
}

\begin{abstract}
The near-surface (400-500 $\AA$ ) of p-GaN exposed to high density plasmas is found to become more compensated through the introduction of shallow donors. At high ion fluxes or ion energies there can be type-conversion of this surface region. Two different methods for removal of the damaged surface were investigated; wet etching in $\mathrm{KOH}$, which produced self-limiting etch depths or thermal annealing under $\mathrm{N}_{2}$ which largely restored the initial electrical properties.
\end{abstract}

\section{INTRODUCTION}

Very little work has been performed to understand the effect of plasma damage on p-GaN. Shul et.al. [1] reported that the sheet resistance of p-GaN increased upon exposure to Inductively Coupled Plasmas (ICP) of pure Ar. The increases were almost linearly dependent on ion energy $(90 \%$ increase at $-350 \mathrm{eV})$, but weakly dependent on ion flux $\left(\sim 25 \%\right.$ increase at $\sim 10^{17}$ ions $\left.\mathrm{cm}^{-2} \cdot \mathrm{s}^{-1}\right)$.

Most past work in this area has focused on n-type material. The sheet resistances of GaN [2], InGaN [3], InAlN [3] and InN [3] samples were found to increase in proportion to ion flux and ion energy in an Electron Cyclotron Resonance (ECR) Ar plasma. Ren et.al. [4,5] examined the effect of $\mathrm{ECR} \mathrm{BCl}_{3} / \mathrm{N}_{2}$ and $\mathrm{CH}_{4} / \mathrm{H}_{2}$ plasmas on the electrical performance of InAlN and GaN channel field effect transistors. They found that hydrogen passivation of the Si doping in the channel may occur if $\mathrm{H}_{2}$ is a part of the plasma chemistry and that preferential loss of $\mathrm{N}_{2}$ degraded the rectifying properties of Schottky contacts deposited on plasma-exposed surface. Ping et.al. [6,7] found more degradation in $\mathrm{GaN}$ Schottky contacts exposed to $\mathrm{Ar}$ plasmas relative to $\mathrm{SiCl}_{4}$ exposure, which would be expected on the basis of the faster etch rate with the latter and hence improved damage removal. In general it is found the ion damage tends to increase the ntype doping level at the surface, most likely through preferential loss of $\mathrm{N}_{2}$, and that the bandedge photoluminescence intensity decreases through introduction of non-radiative levels [8-12].

Understanding the effects of plasma-induced damage in GaN has become more important as the interest in electronic devices for high temperature, high power applications has increased. One clear example is in the fabrication of GaN/AlGaN heterojunction bipolar transistors (HBTs) [13-15] or GaN bipolar junction transistors (BJTs) [16] where it is necessary to etch down to both a p-type base layer and an n-type 
subcollector layer. Energetic ion damage may result in increased surface and bulk leakage currents and changes in the electrical properties of the near-surface region through a change in $\mathrm{Ga} / \mathrm{N}$ stoichiometry [1]. In other compound semiconductor systems it is often possible to remove plasma-damaged regions using slow wet chemical etching [17]. In the GaN system, much less is known about the electrical effects of dry etch damage, and its subsequent removal by wet etching or annealing.

We describe the results of experiments in which $\mathrm{p}-\mathrm{GaN}$ was exposed to Inductively Coupled Plasmas (ICP) of $\mathrm{Cl}_{2} / \mathrm{Ar}, \mathrm{H}_{2}$ or Ar. The changes in electrical properties were measured by diode breakdown voltage.

\section{EXPERIMENTAL}

A schematic of the final Schottky diode structures is shown in Figure 1. Plasma exposures were performed with the contacts in place. The layer structure consisted of $1 \mu \mathrm{m}$ of undoped $\mathrm{GaN}\left(\mathrm{n}-5 \times 10^{16} \mathrm{~cm}^{-3}\right)$ grown on a c-plane $\mathrm{Al}_{2} \mathrm{O}_{3}$ substrate, followed by $0.3 \mu \mathrm{m}$ of $\mathrm{Mg}$ doped $\left(\mathrm{p}-10^{17} \mathrm{~cm}^{-3}\right) \mathrm{GaN}$. The samples were grown by rf plasma-assisted Molecular Beam Epitaxy [18]. Ohmic contacts were formed with Ni/Au deposited by ebeam evaporation, followed by lift-off and annealing at $750^{\circ} \mathrm{C}$. The $\mathrm{GaN}$ surface was then exposed for $1 \mathrm{~min}$ to $\mathrm{ICP} \mathrm{Cl}_{2} / \mathrm{Ar}, \mathrm{H}_{2}$ or Ar plasmas in a Plasma-Therm 790 System. The $2 \mathrm{MHz}$ ICP source power was varied from $300-1400 \mathrm{~W}$, while the $13.56 \mathrm{MHz}$ rf chuck power was varied from 20-250 W. The former parameter controls ion flux incident on the sample, while the latter controls the average ion energy. Prior to deposition of $250 \mu \mathrm{m}$ diameter $\mathrm{Ti} / \mathrm{Pt} / \mathrm{Au}$ contacts through a stencil mask, the plasma exposed surfaces were either annealed under $\mathrm{N}_{2}$ in a rapid thermal annealing system, or immersed in boiling $\mathrm{NaOH}$ solutions to remove part of the surface. As reported previously it is possible to etch damaged GaN in a self-limiting fashion in hot alkali or acid solutions [19-21]. The current-voltage (I-V) characteristics of the diodes were recorded on an HP 4145A parameter analyzer.

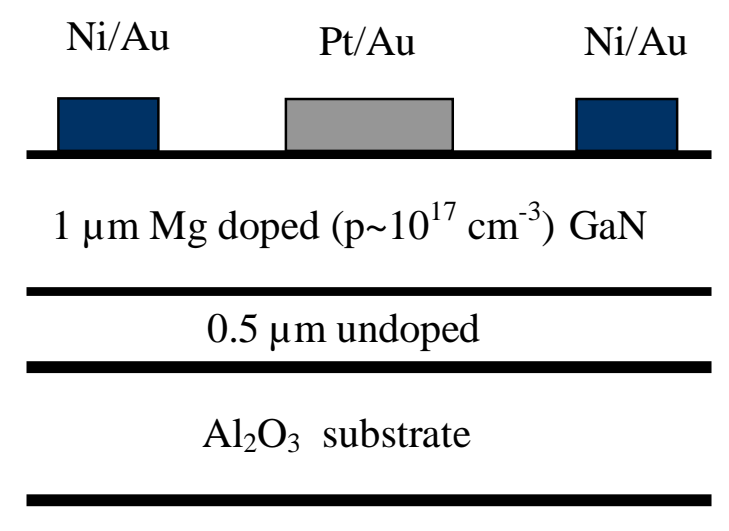

Figure 1. Schematic of completed p-GaN Schottky diode. 


\section{RESULTS AND DISCUSSION}

We observed an increase in reverse breakdown voltage $\left(\mathrm{V}_{\mathrm{B}}\right)$ on the $\mathrm{p}-\mathrm{GaN}$, whose magnitude was dependent on both ion energy and ion flux. The increase in breakdown voltage on the $\mathrm{p}-\mathrm{GaN}$ is due to a decrease in hole concentration in the near-surface region through the creation of shallow donor states. The key question is whether there is actually conversion to an n-type surface under any of the plasma conditions. Figure 2 shows the forward turn-on characteristics of the $\mathrm{p}-\mathrm{GaN}$ diodes exposed to different source power Ar discharges at low source power $(300 \mathrm{~W})$. The turn-on voltage remains close to that of the unexposed control sample. However there is a clear increase in the turn-on voltage at higher source powers, and in fact at $\geq 750 \mathrm{~W}$ the characteristics are those of an n-p junction [22]. Under these conditions the concentration of plasmainduced shallow donors exceeds the hole concentration and there is surface conversion. In other words the metal-p GaN diode has become a metal-n GaN-p GaN junction. We always find that plasma exposed $\mathrm{GaN}$ surfaces are $\mathrm{N}_{2}$-deficient relative to their unexposed state $[1,3,4,5,10]$, and therefore the obvious conclusion is nitrogen vacancies create shallow donor levels. This is consistent with thermal annealing experiments in which $\mathrm{N}_{2}$ loss from the surface produced increased n-type conduction [23,24].

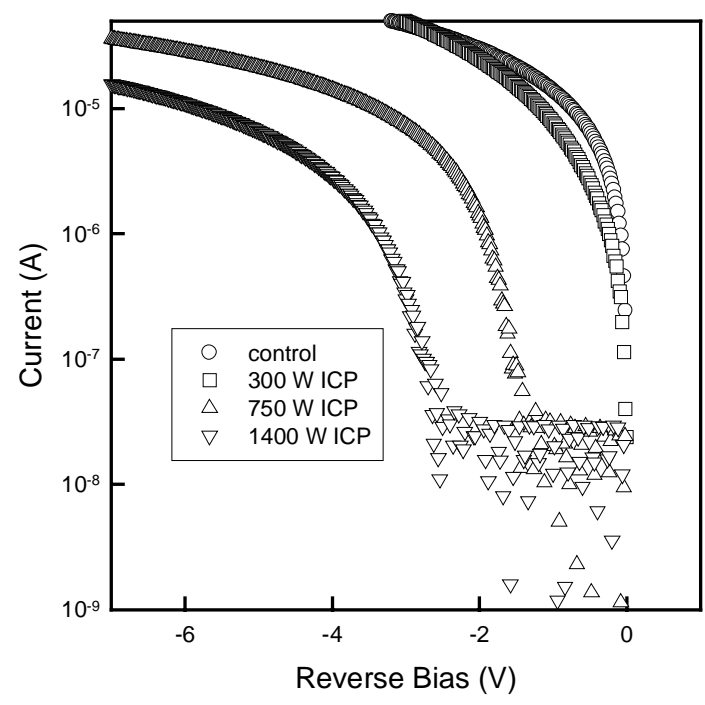

Figure 2. Forward turn-on characteristics of diodes exposed to ICP Ar discharges (150 $\mathrm{W}$ rf chuck power) at different ICP source powers prior to deposition of the Ti/Pt/Au contact. 
The influence of rf chuck power on the diode I-V characteristics is shown in Figure 3 for both $\mathrm{H}_{2}$ and Ar discharges at fixed source power $(500 \mathrm{~W})$. A similar trend is observed as for the source power experiments, namely the reverse breakdown voltage increases, consistent with a reduction in p-doping level near the GaN surface.
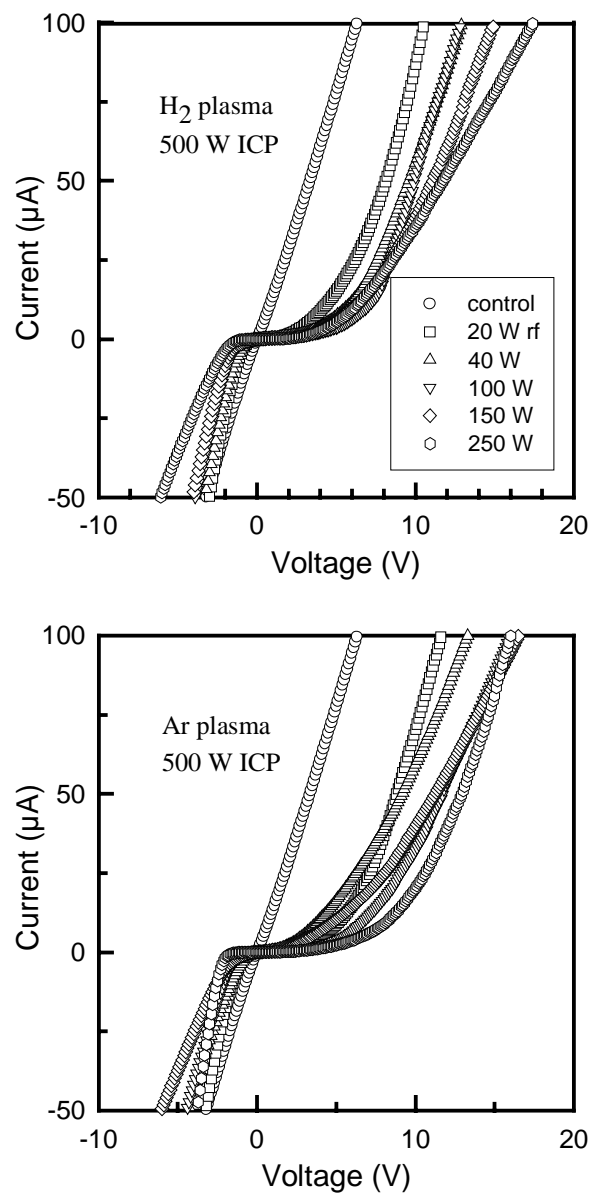

Figure 3. $\mathrm{I}-\mathrm{V}$ characteristics from samples exposed to either $\mathrm{H}_{2}$ (top) or $\mathrm{Ar}$ (bottom) ICP discharges ( $500 \mathrm{~W}$ source power) as a function of rf chuck power prior to deposition of the Ti/Pt/Au contact. The breakdown voltage increases with the rf chuck power employed during the plasma exposure. 
Figure 4 plots breakdown voltage and dc chuck self-bias as a function of the applied rf chuck power. The breakdown voltage initially increases rapidly with ion energy (the self bias plus $\sim 25 \mathrm{~V}$ plasma potential) and saturates above $\sim 100 \mathrm{~W}$ probably due to the fact that sputtering yield increases and some of the damaged region is removed. Note that there are very large changes in breakdown voltage even for low ion energies, emphasizing the need to carefully control both flux and energy. We should also point out that our experiments represent worse-case scenarios because with real etching plasma chemistries such as $\mathrm{Cl}_{2} / \mathrm{Ar}$, the damaged region would be much shallower due to the much higher etch rate. As an example, the sputter rate of $\mathrm{GaN}$ in a $300 \mathrm{~W}$ source power, $40 \mathrm{~W}$ rf chuck power Ar ICP discharge in $\sim 40 \AA \cdot \min ^{-1}$, while the etch rate in a $\mathrm{Cl}_{2} / \mathrm{Ar}$ discharge under the same conditions is $\sim 1100 \AA \cdot \mathrm{min}^{-1}$.

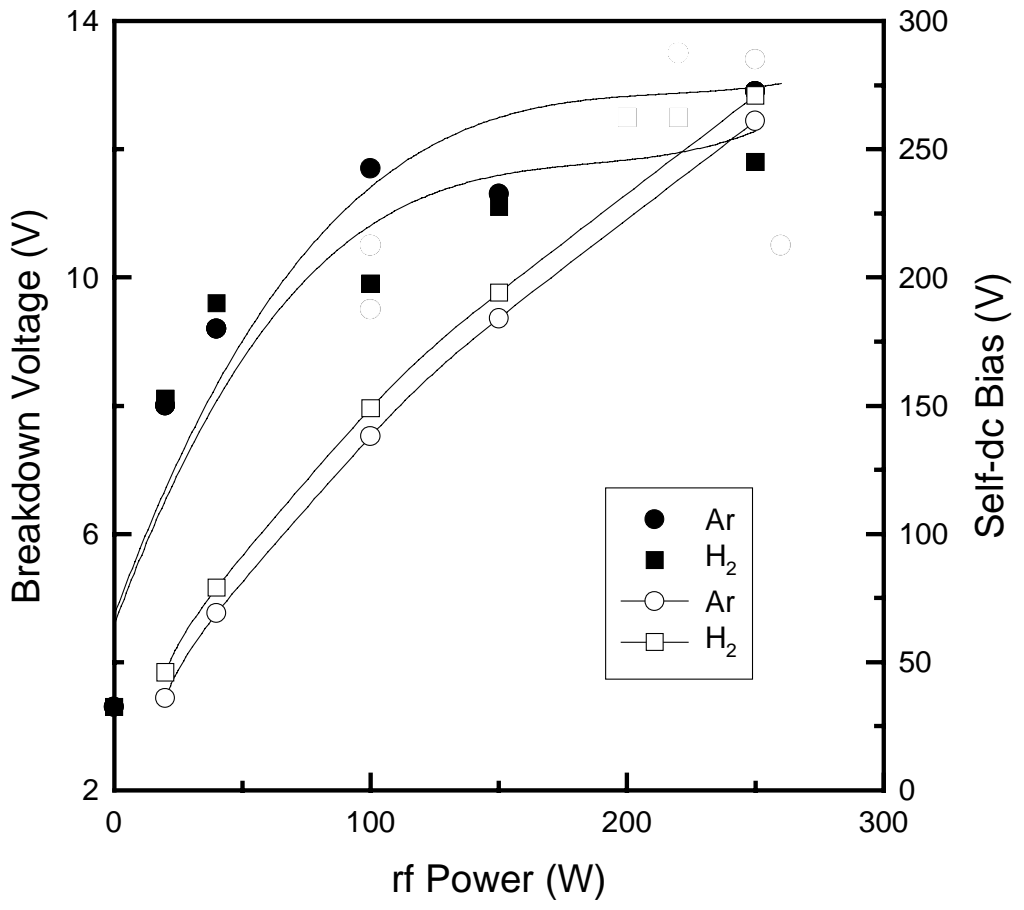

Figure 4. Variation of diode breakdown voltage in samples exposed to $\mathrm{H}_{2}$ or Ar ICP discharges (500 W source power) at different rf chuck powers prior to deposition of the $\mathrm{Ti} / \mathrm{Pt} / \mathrm{Au}$ contact (solid symbols). The dc chuck self-bias during plasma exposure is also shown (open symbols). 
Figure 5 shows I-V characteristics from samples that were wet etched to various depths in $\mathrm{NaOH}$ solutions after exposure to either $\mathrm{Cl}_{2} / \mathrm{Ar}$ or $\mathrm{Ar}$ discharges $(500 \mathrm{~W}$ source power, $150 \mathrm{~W}$ rf chuck power, $1 \mathrm{~min}$ ). For these plasma conditions we did not observe type conversion of the surface. However, we find that the damaged $\mathrm{GaN}$ can be effectively removed by immersion in hot $\mathrm{NaOH}$, without the need for photo- or electrochemical assistance of the etching. The $\mathrm{V}_{\mathrm{B}}$ values increase on $\mathrm{p}-\mathrm{GaN}$ after plasma exposure due to introduction of shallow donor states that reduce the net acceptor concentration.
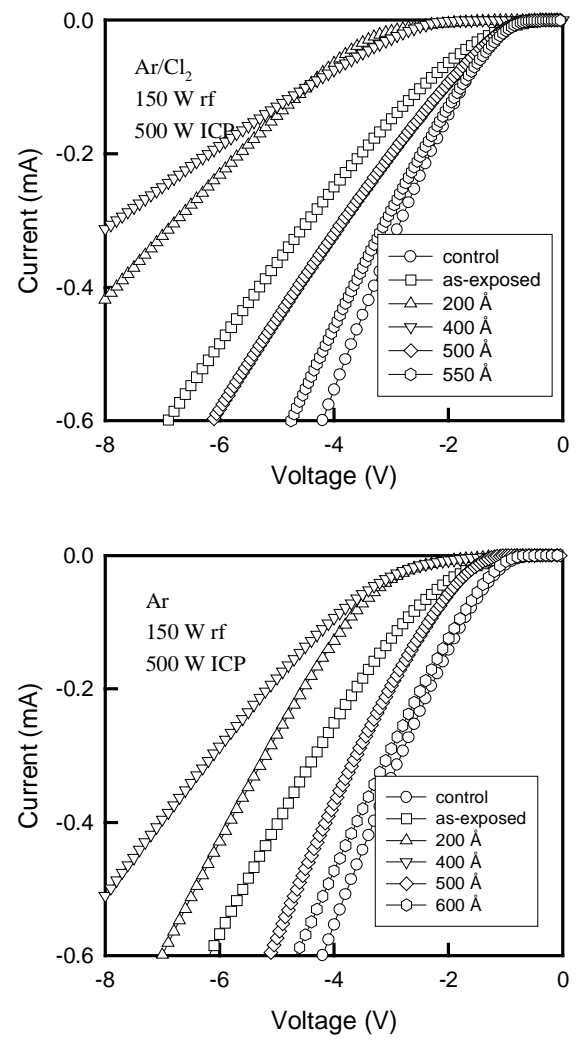

Figure 5. I-V characteristics from $\mathrm{p}-\mathrm{GaN}$ samples exposed to $\mathrm{ICP} \mathrm{Cl}_{2} / \mathrm{Ar}$ (top) or $\mathrm{Ar}$ (bottom) discharges (500 W source power, $150 \mathrm{~W}$ rf chuck power) and wet etched in boiling $\mathrm{NaOH}$ to different depths prior to deposition of the rectifying contact. 
Figure 6 shows the wet etch depth in plasma damaged $\mathrm{p}-\mathrm{GaN}$ as a function of etching time. The etch depth saturates at depths of 500-600A, consistent with the electrical data. It has previously been shown by Kim et.al. [19] that the wet etch depth on thermally- or ion-damaged GaN was self-limiting. This is most likely a result of the fact that defective or broken bonds in the material are readily attacked by the acid or base, whereas in undamaged $\mathrm{GaN}$ the etch rate is negligible. I-V characteristics were recorded from samples exposed to $750 \mathrm{~W}$ source power, $150 \mathrm{~W}$ rf chuck power $(-160 \mathrm{~V}$ dc chuck bias) Ar discharges and subsequently wet etched to different depths using $0.1 \mathrm{M} \mathrm{NaOH}$ solutions before deposition of the Ti/Pt/Au contact. Figure 7 shows the effect of the amount of material removed on the diode breakdown voltage. Within the experimental error of $\pm 12 \%$, the initial breakdown voltage is reestablished in the range $400-450 \AA$. This is consistent with the depth obtained from the etch rate experiments described above. These values are also consistent with the damage depths we established in $\mathrm{n}-\mathrm{GaN}$ diodes exposed to similar plasma conditions [25].

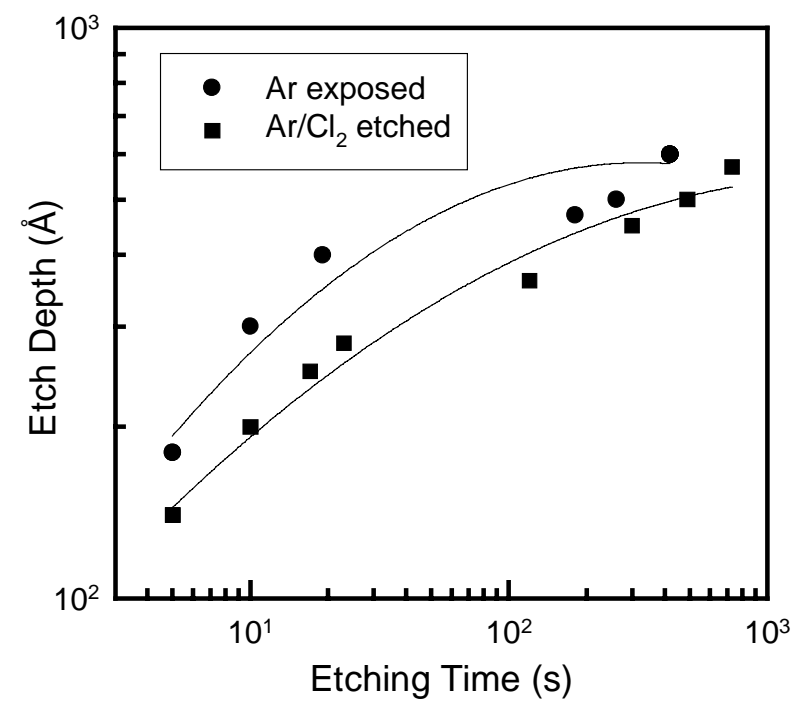

Figure 6. Wet etch depth versus etch time in boiling $0.1 \mathrm{M} \mathrm{NaOH}$ solutions for plasma damaged $\mathrm{p}-\mathrm{GaN}$. 
F99W10.8

https://doi.org/10.1557/S1092578300004762 Published online by Cambridge University Press 


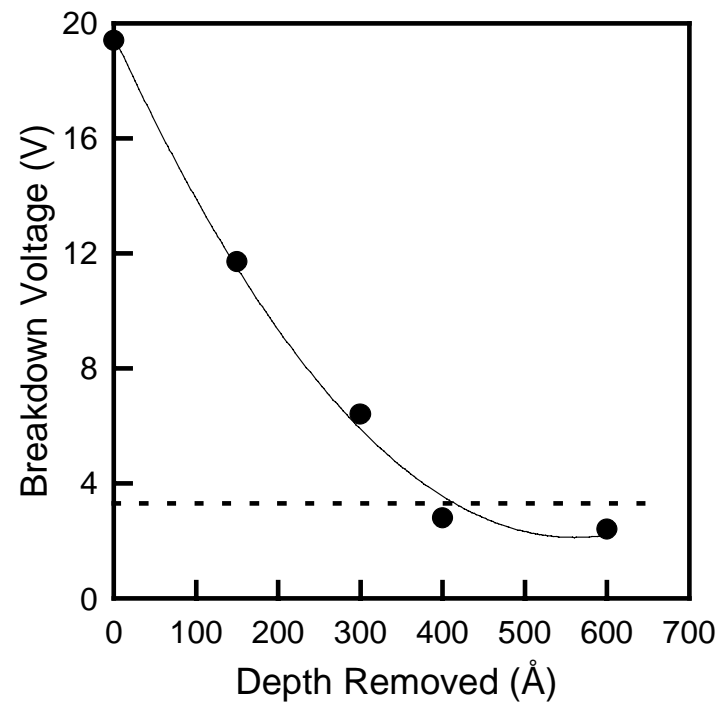

Figure 7. Variation of $\mathrm{V}_{\mathrm{B}}$ with depth of plasma exposed $\mathrm{p}-\mathrm{GaN}$ removed by wet etching prior to deposition of the rectifying contact. The dashed line shows the control value in unexposed p-GaN diodes.

We also performed annealing experiments on the plasma-damaged $\mathrm{p}-\mathrm{GaN}$ at temperatures up to $900^{\circ} \mathrm{C}$ under a $\mathrm{N}_{2}$ ambient. At this temperature the $\mathrm{V}_{\mathrm{B}}$ values were returned to within $10 \%$ of their control values. Annealing at higher temperatures degraded the electrical properties, most likely due to nitrogen loss for the surface.

\section{SUMMARY AND CONCLUSIONS}

ICP plasma exposure of $\mathrm{p}-\mathrm{GaN}$ produced large increases in reverse breadown voltage, independent of the plasma chemistry employed. The results are consistent with creation of nitrogen vacancy-related shallow donors in the near-surface region $(<600 \AA)$. Although not discussed here, the damage was found to accumulate in this region even for very short plasma exposure times (3-4 secs). Two different methods for restoring $V_{B}$ were investigated. Annealing at $900^{\circ} \mathrm{C}$ essentially returned $V_{B}$ to its original, control value, whereas wet etch removal of the damaged surface in boiling $\mathrm{NaOH}$ prior to deposition of the Schottky contact was also effective in restoring the initial electrical properties. 


\section{ACKNOWLEDGMENTS}

The work at UF is partially supported by a DARPA/EPRI grant, No. MDA972-981-0006 (D. Radack and J. Melcher) monitored by ONR (J.C. Zolper) and a NSF grant DMR97-32865 (L.D. Hess). Sandia is a multiprogram laboratory operated by Sandia Corporation, a Lockheed-Martin Company, for the US Department of Energy under contract No. DEAC04-94-AC-85000.

\section{REFERENCES}

1. R.J. Shul, L. Zhang, A.G. Baca, C.G. Willison, J. Han, S.J. Pearton, F. Ren, J.C. Zolper and L.F. Lester, "High Density Plasma-Induced Etch Damage in GaN," Mat. Res. Soc. Symp. Proc. Vol. 573, 271 (1999).

2. C.R. Eddy, Jr. and B. Molnar, "The Effect of H2-Based Etching on GaN," Mat. Res. Soc. Symp. Proc. 395, 745 (1996); "Plasma Etch-Induced Conduction Changes in GaN,” J. Electron. Mater. 28, 314 (1999).

3. S.J. Pearton, J.W. Lee, J.D. MacKenzie, C.R. Abernathy and R.J. Shul, "Dry Etch Damage in InN, InGaN and InAlN," Appl. Phys. Lett. 67, 2329 (1995).

4. F. Ren, J.R. Lothian, S.J. Pearton, C.R. Abernathy, C.B. Vartuli, J.D. MacKenzie, R.G. Wilson and R.F. Karlicek, "Effects of Dry Etching of Surface Properties of III-Nitrides," J. Electron. Mater. 26, 1287 (1997).

5. F. Ren, J.R. Lothian, Y.K. Chen, J.D. MacKenzie, S.M. Donovan, C.B. Vartuli, C.R. Abernathy, J.W. Lee and S.J. Pearton, "Effect of $\mathrm{BCl}_{3}$ Dry Etching on AlInN Surface Properties,” J. Electrochem. Soc. 143, 1217 (1996).

6. A.T. Ping, A.C. Schmitz, I. Adesida, M.A. Khan, A. Chen and Y.W. Yang, "Characterization of RIE Damage to GaN using Schottky Diodes," J. Electron. Mater. 26, 266 (1997).

7. A.T. Ping, Q. Chen, J.W. Yang, M.A. Khan and I. Adesida, "The Effects of RIE Damage on Ohmic Contacts to n-GaN,” J. Electron. Mater. 27, 261 (1998).

8. J.Y. Chen, C.J. Pan and G.C. Chi, "Electrical and Optical Changes in the NearSurface of GaN," Solid-State Electron. 43, 649 (1999).

9. F. Ren, J.R. Lothian, Y.K. Chen, R. Karlicek, L. Tran, M. Schurmann, R. Stall, J.W. Lee and S.J. Pearton, "Recessed Gate GaN FET," Solid-State Electron. 41, 1819 (1997).

10. R.J. Shul, J.C. Zolper, M.H. Crawford, R.J. Hickman, R.D. Briggs, S.J. Pearton, J.W. Lee, R. Karlicek, C. Tran, M. Schurmann, C. Constantine and C. Barratt, "Plasma-Induced Damage in GaN," Proc. Electrochem. Soc. 96-15, 232 (1996).

11. A.S. Usikov, W.L. Lundin, U.I. Ushakov, B.V. Pushnyi, N.N. Schmidt, Y.Y. Zadiranov and T.V. Shubtra, "Electrical and Optical Properties of GaN After Dry Etching," Proc. Electrochem. Soc. 97-14, 57 (1998).

12. K. Satore, A. Matsutani, T. Shirasawa, M. Mori, T. Honda, T. Sakaguchi, F. Kagana and K. Iga, "RIBE of GaN," Mat. Res. Soc. Symp. Proc. 449, 1029 (1997).

13. L.S. McCarthy, P. Kozodoy, S.D. DenBaars, M. Rodwell and U.K. Mishra, $25^{\text {th }}$ Int. Symp. Compound Semicond., Oct. 1998, Nara, Japan.

14. F. Ren, C.R. Abernathy, J.M. Van Hove, P.P. Chow, R. Hickman, J.J. Klaassen, R.F. Kopf, H. Cho, K.B. Jung, R.G. Wilson, J. Han, R.J. Shul, A.G. Baca and S.J. Pearton, “300C GaN HBT,” MRS Internet J. Nitride Semicond. Res. $\underline{3}, 41$ (1998). 
15. J. Han, A.G. Baca, R.J. Shul, C.G. Willison, L. Zhang, F. Ren, A.P. Zhang, G.T. Dang, S.M. Donovan, X.A. Cao, H. Cho, K.B. Jung, C.R. Abernathy, S.J. Pearton and R.G. Wilson, "Growth and Fabrication of GaN HBT," Appl. Phys. Lett. 74, 2702 (1999).

16. S. Yoshida and J. Suzuki, "High Temperature Reliability of GaN MESFET and BJT,” J. Appl. Phys. 85, 7931 (1999).

17. S.J. Pearton, "RIE of Compound Semiconductors," Int. J. Mod. Phys. B $\underline{8}, 1781$ (1994).

18. J.M. Van Hove, R. Hickman, J.J. Klaassen, P.P. Chow and P.P. Ruden, "High Quality GaN Grown by rf-MBE,” Appl. Phys. Lett. 70, 282 (1997).

19. B.J. Kim, J.W. Lee, H.S. Park and T.I. Kim, "Wet Etching of GaN Grown by OMVPE," J. Electron. Mater. 27, L32 (1998).

20. S.A. Stocker, E.F. Schubert and J.M. Redwing, "Crystallographic Wet Etching of GaN,” Appl. Phys. Lett. 73, 2345 (1998).

21. J.-L. Lee, J.K Kim, J.W. Lee, Y.J. Park and T. Kim, "Effect of Surface Treatment by KOH on p-Ohmic Contacts to GaN," Solid-State Electron. 43, 435 (1999).

22. S.M. Sze, Physics of Semiconductor Devices (Wiley-Interscience, NY, 1981).

23. J.C. Zolper, D.J. Rieger, A.G. Baca, S.J. Pearton, J.W. Lee and R.A. Stall, "Sputtered AIN for Annealing GaN," Appl. Phys. Lett. 69, 538 (1996).

24. J. Brown, J. Ramer, K. Zhang, L.F. Lester, S.D. Hersee and J.C. Zolper, "ECR Etching of GaN With and Without $\mathrm{H}_{2}$," Mat. Res. Soc. Symp. Proc. Vol. 395, 702 (1996).

25. X.A. Cao, H. Cho, S.J. Pearton, G.T. Dang, A. Zhang, F. Ren, R.J. Shul, L. Zhang, F. Ren, R.J. Shul, L. Zhang, A.G. Baca, R. Hickman and J.M. Van Hove, "Depth and Thermal Stability of Dry Etch Damage in GaN Schottky Diodes," Appl. Phys. Lett. 75, 232 (1999). 